\title{
Are Intensified Physical Education Sessions Able to Elicit Heart Rate at a Sufficient Level to Promote Aerobic Fitness in Adolescents?
}

\author{
Georges Baquet, Serge Berthoin, and Emmanuel Van Praagh
}

The purpose of this study was to determine the effects of intensified physical education sessions on adolescents ages 11-16 years. They were divided into two experimental groups — high-intensity running group (HIRG) and high-intensity jumping group (HIJG)—and a control group (C). During the sessions, heart rate (HR) was monitored. There was no significant difference between mean HR for HIRG and HIJG, while the mean $H R$ was significantly lower for $C(\mathrm{p}<.001)$. For both HIRG and HIJG, the mean HR was significantly higher for girls than for boys $(\mathrm{p}<.001)$. Our results suggested that these intensified physical education lessons require a high percentage of maximal $H R$ in adolescents and can be used to improve aerobic fitness.

Key words: health, maximal aerobic speed, monitoring, school

n school environments, training studies have been initiated by adding physical education lessons. Kemper et al. (1976) noticed that no training effect was found before puberty. The main reasons were: high training status of prepubertal children, low intensity of classes, nonhomogeneity of maturation between participants, and low specificity of training stimulus. As reviewed by Kemper et al. (1976), most of the physical education lessons were devoted to improving motor coordination rather than endurance and resistance training. Motor coordination increased significantly but not maximal aerobic power or maximal strength. However, Trudeau, Laurencelle, Tremblay, Rajic, and Shephard (1998) emphasized the importance of getting children accustomed to regular and intense physical activity in the

Submitted: July 17, 2000

Accepted: September 21, 2001

Georges Baquet and Serge Berthoin are with the Faculty of Sport Sciences and Physical Education at the University of Lille. Emmanuel Van Praagh is with the Laboratory of Sport Physiology at Blaise Pascal University-Clermont-Ferrand. school curriculum. They concluded that intense physical activity had a long-term impact on physical fitness characteristics. With this aim in view, the status of aerobic running is paradoxical. Indeed, this activity usually programmed into physical education, is directly linked to the notion of health but may be considered annoying by many adolescents. This lack of enthusiasm seems, partly, to arise from the workouts usually proposed. During endurance running, exercises often consist of priority-to-regular and long-distance running at moderate velocity. It seems worthwhile to explore other running paces and, consequently, other practices to make this activity more attractive and, thus, create conditions for progress and enhanced motivation. To control running paces for training during physical education lessons, Berthoin, Manteca, Gerbeaux, and Lensel-Corbeil (1995) proposed the use of the maximal aerobic speed (MAS), namely the lowest speed requiring the maximal oxygen consumption, during a weekly cycle of 12 sessions. On the track, MAS can be assessed using the University of Montreal track test (UMTT; Léger \& Boucher, 1980). This suitable test can easily be used at school (Gerbeaux et al., 1991). Knowing the MAS of the children, it is possible to offer exercises at submaximal, maximal, or supramaximal velocities adapted to each adolescent's capability. Physical activity guidelines for 
promoting fitness and health have suggested a minimum of three 30-min periods of moderate to vigorous physical activity (MVPA; i.e., $60 \%$ of maximal heart rate reserve) per week, for 11-21-year-old adolescents (Sallis \& Patrick, 1994). During physical education lessons, physical educators should be able to reach these recommendations. Nevertheless, exercise physiologists frequently noticed that most of the physical education lessons are not of sufficient intensity. This lack of intensity might prevent the desired physiological responses. As suggested by physical activity guidelines for health promotion, physical education lessons are generally not intensive enough. Therefore, the purpose of this study was to determine the effects of intensified physical education sessions on 11-16-year-old adolescents. These lessons were designed to elicit a mean heart rate reserve of $60 \%$ over the entire lesson (U.S. Department of Health and Human Services, 1996).

\section{Method}

\section{Participants}

Three hundred forty-five secondary-school children (boys: $M$ age $=13.1$ years, $S D=1.4$; girls: $M$ age $=12.8$ years, $S D=1.7$ ) participated in the study. They were divided into two experimental groups: a high-intensity running group (HIRG; 51 boys, 37 girls) and a high-intensity jumping group (HIJG; 71 boys, 51 girls). A third group served as a control ( $C ; 81$ boys, 54 girls). Each group had two physical education lessons per week for a total duration of $3 \mathrm{hr}$. The study was conducted during the mandatory physical education lessons.

\section{Anthropometry}

Height and body mass were measured with a wall stadiometer (Vivioz Medical) and a calibrated balance beam (Tanita TBF 543, Sindelfingen, Germany). The percentage of body fat was obtained from skinfold thickness measured at three sites (biceps, triceps, and calf) and calculated according to Lohman (1992). The participants' characteristics are presented in Table 1.

\section{Maximal Aerobic Speed}

The participants performed a modified version of the 20-m shuttle run test (20-MST; Léger, Mercier, Gadoury, \& Lambert, 1988), adapted for children and adolescents by Gerbeaux et al. (1991). The maximal speed (MS in $\mathrm{km} \cdot \mathrm{h}^{-1}$ ) reached at the last completed stage was retained. As it was demonstrated that the MS (shuttle run) underestimated the MAS, the MS was converted into MAS ac- cording to the formula proposed by Gerbeaux et al. (1991): MAS $=2.4 *$ MS -14.7 . For example, a pupil whose MS $(20$ MST) was $13 \mathrm{~km} \cdot \mathrm{h}^{-1}$ had a MAS (conventional running) rounded up to $17 \mathrm{~km} \cdot \mathrm{h}^{-1}\left(2.4^{*} 13-14.7=16.5\right)$. During physical education lessons, the velocity of the running exercises was expressed as a percentage of MAS.

\section{Intensified Physical Education Lessons}

Intensified physical education lessons took place during a 10-week program. For the experimental groups, the intensity was gradually increased during the program. French adolescents have $3 \mathrm{hr}$ of physical education, divided into two lessons ( $2 \mathrm{hr}$ and $1 \mathrm{hr}$ ). In a $1-\mathrm{hr}$ lesson, only $40 \mathrm{~min}$ are effectively devoted to physical education. Children must move to the sports hall and dress before and after the lesson. In a sequence of $2 \mathrm{hr}$, only $90 \mathrm{~min}$ were devoted to physical education. The experimental groups (HIRG and HIJG) performed one lesson of two usual physical education hours (gymnastics). The second lesson ( $1 \mathrm{hr}$ ) was specifically designed to improve the adolescents' aerobic fitness. Over 10 weeks, HIRG performed a high-intensity training program with specific sessions of $30 \mathrm{~min}$, which consisted of short intermittent exercises (10 or $20 \mathrm{~s}$ ) of running at $100-120 \%$ of MAS. The second group (HIJG) performed a high-intensity training program with specific sessions of 30-40 min that consisted of jumping and running. This program was made up of short intermittent exercises ( 5 or $10 \mathrm{~s}$ ), with horizontal and vertical jumps, and short, intermittent exercises with sprints (5 s) or running (10s) at $100 \%$ of MAS. A control group had

Table 1. Anthropometric characteristics of boys and girls

\begin{tabular}{|c|c|c|c|c|c|c|}
\hline \multirow{2}{*}{ Boys } & \multicolumn{2}{|c|}{ HIRG $(n=51)$} & \multicolumn{2}{|c|}{ HIJG $(n=71)$} & \multicolumn{2}{|c|}{$C(n=81)$} \\
\hline & $M$ & $S D$ & $M$ & $S D$ & $M$ & $S D$ \\
\hline$e($ & & 1 & 10 & 1.50 & 3.10 & 1.30 \\
\hline ) & 52.10 & & 40 & & 46.80 & 12.00 \\
\hline & 1.58 & 0.18 & 1.59 & & 1.55 & 0.12 \\
\hline$\%$ Body fat & 16.90 & 7.60 & 16.30 & 6.80 & 18.00 & 7.50 \\
\hline \multirow[t]{2}{*}{ Girls } & \multicolumn{2}{|c|}{ HIRG $(n=37)$} & \multicolumn{2}{|c|}{ HIJG $(n=51)$} & \multirow{2}{*}{\multicolumn{2}{|c|}{$C(n=54)$}} \\
\hline & & $\mathrm{cn}$ & $M$ & co & & \\
\hline & & & & & 12.80 & 2.20 \\
\hline & 53.20 & 11. & 52.00 & 10.3 & 49.70 & 10.40 \\
\hline & 1.58 & 0. & 1.57 & 0. & 1.56 & 0.08 \\
\hline$\%$ Body fat & 24.70 & 6.10 & 24.20 & 6.20 & 28.60 & $7.60^{*}$ \\
\hline
\end{tabular}

Note. $\mathrm{HIRG}=$ high-intensity running group; $\mathrm{HIJG}=$ high-intensity jumping group; $C=$ control group; $M=$ mean; $S D=$ standard deviation.

*Significantly different from the other groups $(p<.05)$. 
$3 \mathrm{hr}$ of physical education not specifically designed to improve aerobic fitness (gymnastics and badminton). For the experimental groups, the increase in exercise intensity throughout the lessons was obtained by increasing the velocity of the runs from $100 \%$ to $120 \%$ of MAS at the end of the program. These exercises were performed on a short track (see Figure 1). On this track, adolescents were placed in different corridors according to their MAS. They had to cover the distance between the two extremities in 10 or $20 \mathrm{~s}$. After 10 or $20 \mathrm{~s}$ of recovery, they turned around and repeated the run in the opposite direction. Concerning the jumping program, the increase in intensity throughout the sessions was obtained by increasing the number of repetitions. Examples of lessons are presented in Tables 2 and 3.

\section{Heart Rate Monitoring}

Heart rate (HR) was continuously monitored during the 20-MST and during physical education lessons, using a HR monitor (Polar Accurex+, Polar Electro, Kempele, Finland). This compact device is easy to attach without restricting children's movements. Heart rate was monitored at 5 -s intervals. The HR records were validated when the entire training period was recorded, and artifacts did not exceed $2 \%$ of each record. The maximal HR (HRmax) was the highest HR value measured during the 20-MST. During the physical education lessons, $\mathrm{HR}$ was measured and averaged (HRmean) over the 30 min of intensified physical education lessons for HIRG and HIJG and over 60 min for C (90 min of effective physical education lesson minus 30 min of warmup and teacher explanations). Three to four HR records were performed for each adolescent over the 10-week program. A total of 877 records were obtained during physi- cal education lessons; 293 for HIRG, 393 for HIJG, and 191 for C. Measured $\mathrm{HR}$ was expressed either as beats per minute (bpm) or as a percentage of HRmax (\%HRmax). According to Stratton (1996), exercise times were expressed in time spent above a training threshold of 50 , 60 , or $75 \%$ of heart rate reserve (HRR; see Table 4 ).

\section{Statistical Analysis}

Results are presented as means and standard deviations. Experimental means were compared through a two-factor analysis of variance (ANOVA; sex and exercise type). The Scheffé post hoc test was used when the ANOVA revealed a significant influence of sex or type

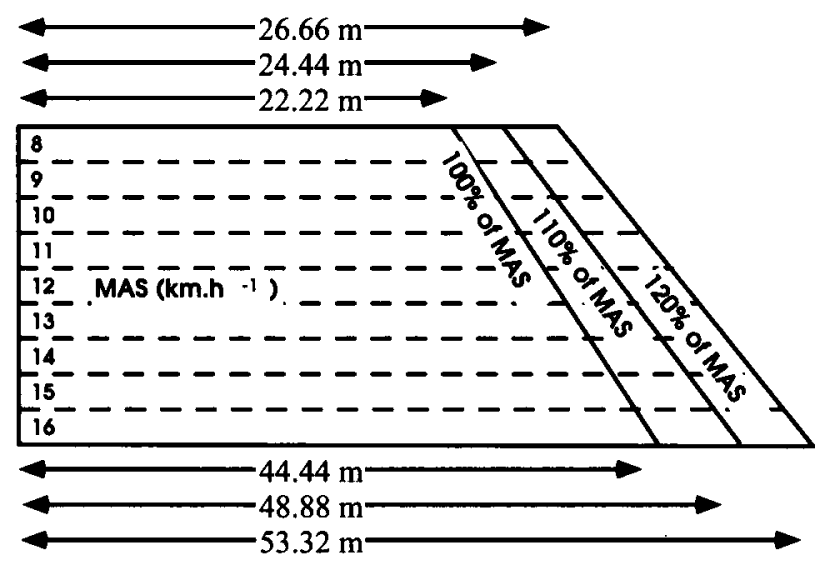

Figure 1. Short track for intermittent exercise. On this track, adolescents were placed in different corridors according to their maximal aerobic speed. They had to cover the distance between the two extremities in $10 \mathrm{~s}$. After $10 \mathrm{~s}$ of recovery, they turned around and repeated the run in the opposite direction.

Table 2. An example of three lessons for HIRG

\begin{tabular}{|c|c|c|c|c|}
\hline \multirow[t]{2}{*}{ Lessons } & \multirow{2}{*}{$\begin{array}{l}\text { Short intermittent running exercises } \\
\text { Warm-up }\end{array}$} & \multirow{2}{*}{$\begin{array}{l}\text { Exercise and recovery time } \\
\text { Real work time: } 28 \mathrm{~min}\end{array}$} & \multicolumn{2}{|c|}{ HRmean (\%HRmax) } \\
\hline & & & $M$ & $S D$ \\
\hline \multirow[t]{2}{*}{1} & $\begin{array}{l}3 \text { sets of } 10 \text { trials for } 10 \mathrm{~s} \text { at } 100 \% \\
\text { of MAS }\end{array}$ & $\begin{array}{l}\text { Recovery: } 10 \mathrm{~s} \text { between each repetition and } 3 \mathrm{~min} \\
\text { between each set }\end{array}$ & & \\
\hline & Stretching & Stretching: $5 \mathrm{~min}$ & 74.3 & 0.9 \\
\hline \multirow[t]{2}{*}{5} & $\begin{array}{l}3 \text { sets of } 10 \text { trials for } 10 \mathrm{~s} \text { at } 110 \% \\
\text { of MAS }\end{array}$ & $\begin{array}{l}\text { Recovery: } 10 \mathrm{~s} \text { between each repetition and } 3 \mathrm{~min} \\
\text { between each set }\end{array}$ & & \\
\hline & Stretching & Stretching: $5 \mathrm{~min}$ & 73.1 & 0.4 \\
\hline \multirow[t]{2}{*}{10} & $\begin{array}{l}3 \text { sets of } 10 \text { trials for } 10 \mathrm{~s} \text { at } 120 \% \\
\text { of MAS }\end{array}$ & $\begin{array}{l}\text { Recovery: } 10 \mathrm{~s} \text { between each repetition and } 3 \mathrm{~min} \\
\text { between each set }\end{array}$ & & \\
\hline & Stretching & Stretching: $5 \mathrm{~min}$ & 77.0 & 0.9 \\
\hline
\end{tabular}

Note. HIRG = high-intensity running group; HRmean = mean heart rate; \%HRmax = percentage of maximal heart rate; $M=$ mean; $S D$ $=$ standard deviation; MAS = maximal aerobic speed; warm-up $=2$ sets of 10 trials of 10 -s running at 80 and $90 \%$ of MAS, with $10 \mathrm{~s}$ recovery between each repetition and 3 min between each set. 
of exercise. In the case of significant differences in anthropometric parameters between groups, a one-factor (group) analysis of covariance (ANCOVA) was performed with the anthropometric parameter as the covariate. The level for significance was set at $p<.05$.

\section{Results}

The ANOVA revealed sex and type of exercise effects but no interaction between sex and type of exercise. Results are presented in Tables 5 and 6 by sex and type of exercise. For both boys and girls, HRmeans of HIRG and HIJG were not significantly different (156 \pm 12 vs. $154 \pm 12 \mathrm{bpm}$, respectively) but were significantly higher than for $\mathrm{C}(136 \pm 13 \mathrm{bpm}, p<.001)$. A significant difference was also found between HRmean, expressed in \%HRmax, obtained for HIRG (75.6 $\pm 5.4 \% \mathrm{HRmax})$ or HIJG (75.5 $\pm 5.6 \%$ HRmax), and C $(66.1 \pm 5.8 \%$ HRmax, $p<.001)$. For both HIRG and HIJG, HRmean was significantly higher in girls than in boys $(p<.001)$. For HIRG and HIJG, the lesson percentage of time spent above a training threshold of 50,60 , and $75 \%$ of $\mathrm{HRR}$ was significantly higher in girls than in boys $(p<.05)$. For both sexes, this time was significantly higher in HIRG and HIJG than C. We noticed a significant difference only between HIRG and HIJG above a training threshold of $60 \%$ of HRR for boys. For girls, the descriptive results showed a significant difference in the percentage of body fat (\% body fat) between $\mathrm{C}$ and the experimental groups. To test a possible influence of percentage body fat on HR measures, an ANCOVA was performed, with percentage body fat as the covariate, to compare the groups' results. The results of the ANCOVA revealed that $H R$ measurement differences were independent of the percentage body fat for girls.

\section{Discussion}

In the control group, HRmean was $136 \pm 13 \mathrm{bpm}$ or $66 \%$ of HRmax, which represented less than $50 \%$ of the HRR. These results agreed with those of Gavarry et al. (1998), who measured a HRmean of $128 \mathrm{bpm}$ during

Table 3. An example of three short intermittent mixed running and jumping sessions

\begin{tabular}{|c|c|c|c|c|}
\hline \multirow[t]{2}{*}{ Lessons } & \multirow{2}{*}{$\begin{array}{l}\text { Short intermittent running } \\
\text { and jumping exercises }\end{array}$} & \multirow[t]{2}{*}{ Exercise and recovery time } & \multicolumn{2}{|c|}{ HRmean (\%HRmax) } \\
\hline & & & $M$ & $S D$ \\
\hline 1 & $\begin{array}{l}6 \text { sets of } 10 \text { trials for } 10 \mathrm{~s} \\
\text { Stretching }\end{array}$ & $\begin{array}{l}\text { Real work time: } 34 \text { min } \\
\text { Recovery: } 10 \mathrm{~s} \text { between each repetition and } 3 \text { min between each set } \\
\text { Stretching: } 5 \text { min }\end{array}$ & .2 & 0.1 \\
\hline 5 & $\begin{array}{l}5 \text { sets of } 12 \text { trials for } 10 \mathrm{~s} \\
\text { Stretching }\end{array}$ & $\begin{array}{l}\text { Real work time: } 36 \mathrm{~min} \\
\text { Recovery: } 10 \mathrm{~s} \text { between each repetition and } 4 \mathrm{~min} \text { between each set }\end{array}$ & & \\
\hline 10 & $\begin{array}{l}4 \text { sets of } 18 \text { trials for } 10 \mathrm{~s} \\
\text { Stretching }\end{array}$ & $\begin{array}{l}\text { Stretching: } 5 \mathrm{~min} \\
\text { Real work time: } 39 \mathrm{~min} \\
\text { Recovery: } 10 \mathrm{~s} \text { between each repetition and } 5 \mathrm{~min} \text { between each set }\end{array}$ & 79.6 & 0.7 \\
\hline & & Stretching: $5 \mathrm{~min}$ & 81.1 & 0.3 \\
\hline
\end{tabular}

Note. HRmean = mean heart rate; $\% \mathrm{HRmax}=$ percentage of maximal heart rate; $M=$ mean; $S D=$ standard deviation. The children performed three circuits: (a) 15 min hurdles; the hurdle height did not exceed $0.4 \mathrm{~m}$ for $10 / 20$ s lessons and $0.3 \mathrm{~m}$ for $10 / 10$ s exercises; (b) 15 hops; (c) 15 slats or cones or elastic rope. They practiced, under different forms, skipping, running, and jumping.

Table 4. Maximum heart rate reserve threshold estimated from age-related maximum and resting heart rates (25)

\begin{tabular}{|c|c|c|c|c|c|c|c|c|}
\hline \multirow{3}{*}{$\begin{array}{l}\text { Age } \\
\text { (years) }\end{array}$} & \multirow{2}{*}{\multicolumn{2}{|c|}{$\begin{array}{l}\text { Resting heart rate } \\
\text { (bpm) }\end{array}$}} & \multicolumn{6}{|c|}{$\%$ HRmax reserve } \\
\hline & & & \multicolumn{2}{|c|}{50} & \multicolumn{2}{|c|}{60} & \multicolumn{2}{|c|}{75} \\
\hline & Boys & Girls & Boys & Girls & Boys & Girls & Boys & Girls \\
\hline $10-12$ & 85 & 90 & 143 & 145 & 154 & 156 & 171 & 173 \\
\hline $12-14$ & 80 & 85 & 140 & 143 & 152 & 154 & 170 & 171 \\
\hline $14-16$ & 75 & 80 & 138 & 140 & 150 & 152 & 169 & 170 \\
\hline
\end{tabular}

Note. HRmax = maximum heart rate. 
standard physical education lessons. HRmean from HIRG and HIJG were higher during physical education lessons than those reviewed in the literature by Stratton (1996). This author reported large variation coefficients in many investigations, which reflected individual differences in HR during the same physical education lesson: $14 \%$ for swimming (Faulkner, Greey, \& Hunsicker, 1963), 19\% for gymnastics (Knowles, 1978), and 14.5\% for volleyball (Holmes \& Mercer, 1988). Indeed, during physical education lessons, exercise intensity is rarely individualized to the capacity of each adolescent, and the lesson goal is generally to improve motor skills. In the present study, running exercises were expressed in the percentage of each adolescent's MAS. With a track especially designed for short intermittent runs, adolescents ran at the same relative velocity (percentage of MAS) over the same time but not the same distance.
Therefore, for the experimental groups (HIRG and HIJG), the coefficient of HRmean variation was about $8 \%$ in boys and girls. It was less than those reported in the literature when the intensity of the exercises could not be controlled, but it was higher than for circuit training (2\%; Holmes \& Mercer, 1988). In addition, our results were based on a large number of participants in contrast to other studies. These intensified lessons were inspired by the habitual spontaneous activity in children. We tried to reproduce their recreational games. During recreation periods, the children's spontaneous activity looked like intermittent training. Bailey et al. (1994) showed that the medium duration of high-intensity activities in children was $3 \mathrm{~s}$, and $95 \%$ of highintensity activities lasted less than $15 \mathrm{~s}$. Finally, jumping exercises can be used in the framework of an endurance running program like short, intermittent exercises

Table 5. Maximal aerobic speed and heart rate measurements for boys

\begin{tabular}{|c|c|c|c|c|c|c|}
\hline \multirow[t]{2}{*}{ Boys } & \multicolumn{2}{|c|}{ HIRG $(n=51)$} & \multicolumn{2}{|c|}{ HIJG $(n=71)$} & \multicolumn{2}{|c|}{$C(n=81)$} \\
\hline & $M$ & $S D$ & $M$ & $S D$ & $M$ & $S D$ \\
\hline HR records $(n)$ & \multicolumn{2}{|c|}{173} & \multicolumn{2}{|c|}{239} & \multicolumn{2}{|c|}{117} \\
\hline $\operatorname{MAS}\left(\mathrm{km} \cdot \mathrm{h}^{-1}\right)$ & 12.0 & 1.9 & 12.0 & 2.0 & 12.0 & 1.8 \\
\hline HRmax (bpm) & 207.0 & $8.0^{* *}$ & 204.0 & 11.0 & 205.0 & 9.0 \\
\hline HRmean (bpm) & 154.0 & 12.0 & 152.0 & 13.0 & 134.0 & $13.0^{* * *}$ \\
\hline HRmean (\% HRmax) & 74.5 & 5.2 & 74.6 & 5.9 & 59.4 & $16.9^{* * *}$ \\
\hline$\%$ exercise time spent above $50 \%$ HRR & 65.7 & 9.9 & 62.9 & 12.4 & 39.1 & $18.3^{* * *}$ \\
\hline$\%$ exercise time spent above $60 \%$ HRR & 57.3 & $10.5^{* * *}$ & 53.2 & $13.0^{* * *}$ & 24.7 & $15.8^{* * *}$ \\
\hline$\%$ exercise time spent above $75 \%$ HRR & 39.1 & 18.7 & 35.2 & 19.9 & 10.1 & $9.9^{* * *}$ \\
\hline
\end{tabular}

Note. $\mathrm{HIRG}=$ high-intensity running group; $\mathrm{HIJG}=$ high-intensity jumping group; $\mathrm{C}=$ control group; $\mathrm{HR}=$ heart rate; $\mathrm{MAS}=$ maximal aerobic speed; $H R \max =$ maximal heart rate; $H R$ mean = mean heart rate; $H R R=$ heart rate reserve.

${ }^{* *}$ Significantly different from the other groups $(p<.01)$.

*** Significantly different from the other groups $(p<.001)$.

Table 6. Maximal aerobic speed and heart rate measurements for girls

\begin{tabular}{|c|c|c|c|c|c|c|}
\hline \multirow[t]{2}{*}{ Girls } & \multicolumn{2}{|c|}{ HIRG $(n=37)$} & \multicolumn{2}{|c|}{ HIJG $(n=51)$} & \multicolumn{2}{|c|}{$C(n=54)$} \\
\hline & $M$ & $S D$ & $M$ & $S D$ & $M$ & $S D$ \\
\hline HR records $(n)$ & \multicolumn{2}{|c|}{120} & \multicolumn{2}{|c|}{154} & \multicolumn{2}{|c|}{74} \\
\hline $\operatorname{MAS}\left(\mathbf{k m} \cdot \mathrm{h}^{-1}\right)$ & 9.8 & 0.8 & 10.1 & 0.9 & 10.0 & 0.7 \\
\hline HRmax (bpm) & 204.0 & 9.0 & 204.0 & 10.0 & 205.0 & 7.0 \\
\hline HRmean (bpm) & 158.0 & 12.0 & 157.0 & 11.0 & 138.0 & $14.0^{* * *}$ \\
\hline HRmean (\% HRmax) & 77.3 & 5.4 & 77.0 & 4.6 & 67.6 & $6.3^{* * *}$ \\
\hline$\%$ exercise time spent above $50 \%$ HRR & 68.8 & 10.1 & 65.3 & $11.2^{* * *}$ & 40.9 & $21.4^{* * *}$ \\
\hline$\%$ exercise time spent above $60 \%$ HRR & 58.2 & 12.0 & 55.7 & 10.5 & 27.1 & $18.7^{* * *}$ \\
\hline$\%$ exercise time spent above $75 \%$ HRR & 42.4 & 17.9 & 41.6 & 15.0 & 11.4 & $10.9 * * *$ \\
\hline
\end{tabular}

Note. HIRG = high-intensity running group; $H I J G=$ high-intensity jumping group; $C=$ control group; $H R=$ heart rate; $M A S=$ maximal aerobic speed; $H R \max =$ maximal heart rate; $H R$ mean = mean heart rate; $H R R=$ heart rate reserve.

${ }^{* * *}$ Significantly different from the other groups $(p<.001)$. 
(10 s-10 s or $20 \mathrm{~s}-20 \mathrm{~s}$ ). These activities increased cardiorespiratory function to the same level as HIRG and attempted to mimic children's habitual recreative activity. However, adolescents are confronted with overcoming motor, balance, and coordination problems. It was more difficult for girls to coordinate multiple jumps, perhaps due to lower force production and greater body mass. During puberty and adolescence, the strength differences may be caused, in part, by a continued increase in subcutaneous fat in girls (Kemper, 1986) and an increase in muscle size and lean body mass in boys (Malina, 1986) and, in part, by such factors as hormonal, neuromuscular, or biomechanical differences or differences in the physical activity levels of boys and girls (Blimkie, 1989). Falgairette, Gavarry, Bernard, and Hebbelinck (1997) showed that boys experienced more spontaneous activity at school than girls, but their physical and metabolic activity were identical. The mean \%HRmax was found to be significantly higher in girls than in boys $(+2.5 \%, p<.001)$, and the percentage of exercise time spent above a training threshold from 50 to $75 \%$ of HRR was significantly higher in girls $(4.6 \%)$ than in boys $(1.8 \%)$. These results are similar to those observed by Gavarry et al. (1998), who reported that during physical education lessons girls reached a $2 \%$ higher mean HRR than boys, without a significant age effect. In addition, the difference of HRmean measured between boys and girls $(+4 \mathrm{bpm})$ was similar to the difference presented by Stratton (1996). These differences could be explained by a higher percentage of body fat in girls. In addition, Bar-Or (1983) noticed that the girls' HR could be 20 bpm higher than that of boys for the same relative running intensity.

According to Sallis, Buono, Roby, Micale, and Nelson (1993), the HRmeans for HIRG and HIJG represented approximately $60 \%$ of the HRR for adolescents ages 11-16 years. To achieve a moderate level of physical activity, children should be moving for at least $50 \%$ (or $20 \mathrm{~min}$ ) of the lesson time, with a heart rate between 50 and $59.9 \%$ of HRR. To achieve a vigorous level, they should be in excess of $60 \%$ HRR of the lesson time (Sallis \& Patrick, 1994). Although Gavarry et al. (1998) noticed that adolescents had the greatest physical activity during physical education lessons, Stratton (1996) revealed that physical education lessons did not usually elicit $\mathrm{HR}$ values likely to increase fitness. In our study, the two guidelines were achieved with these intensified lessons, while $\mathrm{C}$ sessions only reached the first health-related goal (see Tables 5 and 6 ).

Physical education is essential to promote long-term health and fitness, and physical educators must promote adolescents' physical activity during school programs. They have to be engaged in moderate-to-vigorous physical activity to fully benefit from training activities. It must be emphasized that school is the only time when all adolescents must practice a compulsory physical activity or be physically active. However, setting up three physical education sessions per week requiring moderate-to-vigorous level exertion is difficult for physical educators. The intensified sessions proposed in the present study, if performed regularly over a period of time, may result in improvements in aerobic fitness.

\section{Conclusion}

Our results suggested that the intensified physical education lessons presented in this study require a high percentage of HRmax in adolescents. The intermittent exercises are original and can be an alternative to continuous exercise. Exercise variety enhances the attractiveness of the program and is, therefore, more motivating for children. To teach children to be physically active and reach fitness goals in physical education lessons, physical educators can use these specific sessions. Moreover, these individualized sessions enable adolescents to practice together and be fully involved in training type activities.

\section{References}

Bailey, R. C., Olson, J., Pepper, S. L., Porszasz, J., Barstow, T. J., \& Cooper, D. M. (1994). The level and tempo of children's physical activities: an observation study. Medicine and Science in Sports and Exercise, 27, 1033-1041.

Bar-Or, O. (1983). Pediatric sports medicine for the practitioner: From physiological principles to clinical applications. New York: Springer-Verlag.

Berthoin, S., Manteca, F., Gerbeaux, M., \& Lensel-Corbeil, G. (1995). Effect of a 12-week training program on maximal aerobic speed (MAS) and running time to exhaustion at $100 \%$ of MAS for students aged 14 to 17 years. The Journal of Sports Medicine and Physical Fitness, 35, 251256.

Blimkie, C. J. R. (1989). Age- and sex-associated variation in strength during childhood: anthropometric, morphologic, neurologic, biomechanical, endocrinologic, genetic, and physical activity correlates. In C. V. Gisolfi \& D. R. Lamb (Eds.). Perspectives in exercise science and sports medicine, Vol. 2. Youth, exercise and sport, (pp. 99-163). Indiana, PA: Benchmark Press.

Falgairette, G., Gavarry, O., Bernard, T., \& Hebbelinck, M. (1997). Evaluation of habitual physical-activity from a week's heart-rate monitoring in French school children. European Journal of Applied Physiology, 74, 153-161.

Faulkner, J., Greey, G., \& Hunsicker, P. (1963). Heart rate during physical education periods. Research Quarterly for Exercise and Sport, 34, 95-98.

Gavarry, O., Bernard, T., Giacomoni, M., Seymat, M., Euzet, J. P., \& Falgairette, G. (1998). Continuous heart rate over 1 week in teenagers aged 11-16 years. European Journal of Applied Physiology, 77, 125-132. 
Gerbeaux, M., Lensel-Corbeil, G., Branly, G., Jacquet, A., Lefranc, J. F., Dierkens, J. M., Savin, A., \& Savin, N. (1991). Estimation de la vitesse maximale aérobie chez les élèves des collèges et lycées [Maximal aerobic speed prediction for high school students]. Science et motricité, 13, 19-26.

Holmes, W., \& Mercer, T. H. (1988). Assessment of physiological load associated with selected curricular activities [Abstract]. In British Association of Sports Sciences Conference Proceedings, Exeter. Presented at the meeting of the British Association of Sports Science, Leeds, England.

Kemper, H. C. G. (1986). Health and fitness of Dutch teenagers: A review. In J. A. P. Day (Ed.), Perspectives in Kinanthropometry (pp. 61-80). Champaign, IL: Human Kinetics.

Kemper, H. C. G., Verschuur, R., Ras, J. G. A., Snel, J., Splinter, P. G., \& Tavecchio, L. W. C. (1976). Effect of 5 versus 3 lessons a week physical education upon the physical development of 12 and 13 year old schoolboys. The Journal of Sports Medicine and Physical Fitness, 16, 319-326.

Knowles, J. E. (1978). The assessment of the physiological load of curricular activities. Research Papers Physical Education, 3, 4-9.

Léger, L., \& Boucher, R. (1980). An indirect continuous running multistage field test: The Université de Montréal track test. Canadian Journal of Applied Sports Science, 5, 77-80.

Léger, L., Mercier, D., Gadoury, C., \& Lambert, J. (1988). The multistage 20 meter shuttle run test for aerobic fitness. Journal of Sports Sciences, 6, 93-101.

Lohman, T. G. (1992). Advances in body composition assessment. Champaign, IL: Human Kinetics.

Malina, R. M. (1986). Growth of muscle tissue and muscle mass. In F. Falkner \& J. M. Tanner (Eds.), Human growth. A comprehensive treatise, Vol. 2. Postnatal Growth Neurobiology (pp. 77-99). New York: Plenum Press.
Sallis, J. F., Buono, M. J., Roby, J. J., Micale, F. G., \& Nelson, J. A. (1993). Seven-day recall and other physical activity selfreports in children and adolescents. Medicine and Science in Sports Exercise, 1, 99-108.

Sallis, J. F., \& Patrick, K. (1994). Physical activity guidelines for adolescents. Pediatric Exercise Science, 6, 302-314.

Stratton, G. (1996). Children's heart rate during physical education lessons: A review. Pediatric Exercise Science, 8 , 215-233.

Trudeau, F., Laurencelle, L., Tremblay,J., Rajic, M., \& Shephard, R. J. (1998). A long-term follow-up of participants in the Trois-Rivières semi-longitudinal study of growth and development. Pediatric Exercise Science, 10, 366-77.

U.S. Department of Health and Human Services (1996). Physical Activity and Health: A report of the Surgeon General. Atlanta, GA: Centers for Disease Control and Prevention, National Center for Chronic Disease Prevention and Health Promotion.

\section{Authors' Notes}

We express our thanks to Gareth Stratton from the Center for Physical Education, Sport and Dance, Liverpool John Moores University for his careful reading and helpful comments concerning this manuscript. Please address all correspondence concerning this article to Berthoin Serge, Laboratoire d'Etudes de la Motricité Humaine, Faculté des Sciences du Sport et de l'Education Physique, 9 rue de l'Université, 59790 Ronchin, France.

E-mail: berthoin@hp-sc.univ-lille2.fr 